Rev. Biol. Trop. 52(1): 171-175, 2004

www.ucr.ac.cr www.ots.ac.cr www.ots.duke.edu

\title{
Gill asymmetry in Labeo ogunensis from Ogun river, Southwest Nigeria
}

\author{
A.A. Ayoade ${ }^{1}$, A.A. Sowunmi*2 \& H.I. Nwachukwu ${ }^{1}$ \\ 1 Hydrobiology and Fisheries Unit, Department of Zoology, University of Ibadan, Nigeria. \\ 2 Biological Sciences Department, Olabisi Onabanjo University, P.M.B.2002, Ago-Iwoye. Nigeria. \\ * corresponding author: dayolegba@yahoo.co.uk \\ Received 13-II-2002. Corrected 19-VIII-2003. Accepted 24-X-2003.
}

\begin{abstract}
Fluctuating asymmetry (FA), often used as indicator of environmental stress, was evaluated in gill rakers and filaments of Labeo ogunensis from Ogun river, Southwest Nigeria. Mean length and weight of $13.68 \pm 1.28 \mathrm{~cm}$ and $59.40 \pm 17.48 \mathrm{~g}$ were respectively recorded. The gill rakers $(\mathrm{t}=-0.919)$ and filaments $(\mathrm{t}=$ $-1.150)$ from both sides were not significantly different. The gill filaments recorded $(0.31 \pm 2.42)$ higher incidence of fluctuating asymmetry (FA) compared with the gill rakers $(0.21 \pm 1.58)$, signifying developmental interference in the population. Fish size and sex were observed to exert minimal influence on FA.
\end{abstract}

Keywords: gills, rakers, filaments, asymmetry, Nigeria.

Fluctuating asymmetry (FA), the most widely used measure of developmental stability, is the random departure from perfect bilateral symmetry. This deviation results either from genetic or environmental stress (Van Valen 1962, Palmer and Strobeck 1986, Graham et al. 1993). The inherent ability to regulate development and to faithfully produce the genetically dictated phenotypes under environmental stress is generally referred to developmental stability. FA therefore measures developmental stability (Van Valen 1962). The need for simple monitoring methods for ecosystem has been greatly stressed, and many models have been proposed as biomarkers for stress responses. FA has a prime attribute of indicating environmental stress at early stages or sub-analytical concentrations, before manifesting at community or ecosystem levels due to incorporation of homeostasis (Graham et al. 1993). This was perhaps responsible for its been highly recommended for ecosystem monitoring (GESAMP 1980).

Ogun river is one of the perennial rivers in Nigeria with characteristics synchronizing typ- ical tropical climate. It has coordinates of $3^{\circ} 28^{\prime \prime} \mathrm{E}$ and $8^{\circ} 41^{\prime \prime} \mathrm{N}$ from its source in Oyo state to $3^{\circ} 25^{\prime \prime} \mathrm{E}$ and $6^{\circ} 35^{\prime \prime} \mathrm{N}$ in Lagos where it enters the Lagos lagoon. Adebisi (1981) gave a detailed description of its hydrology. In areas of high population density the river is used for domestic purposes such as bathing, washing and drinking also acting as sink to mostly organic wastes from abattoirs located along the course. This paper seeks to provide information on FA in gills small sample of Labeo ogunensis (Boulenger) as indicator of environmental stress.

\section{MATERIALS AND METHODS}

The gills from both sides of the head were extracted from 47 fish specimens of L. ogunensis and examined according to Lucky (1977). The gill length were measured and meristic counts of gill rakers and filaments on each arch were counted under microscope (Kisia and Hughes 1992). Gills extracted were analyzed same day to avoid shrinkage (Hughes 1995). 
The gender, standard length and body weight were also determined for each specimens. Gender comparison and relationship between gill meristics from both sides were determined using T-student's test (Sokal and Rohlf 1987). FA was estimated from difference between values of traits on the right and left sides as $\mathrm{A}_{\mathrm{i}}=$ $\left|\mathrm{R}_{\mathrm{i}}-\mathrm{L}_{\mathrm{i}}\right|$ (Palmer and Strobeck 1986, Graham et al. 1993). Relationships between body and gill characteristics were explored using Pearson's and Partial correlations (Sokal and Rohlf 1987, Milton 1999).

\section{RESULTS}

The summary of weight, length, gill meristics for indivdual sexes and the total in L. ogunensis is shown on Table 1. Results of ttest between the sexes, the right and left gill meristics is also presented. The females had higher mean weight compared with males but negligible length differences. The t-test however indicated no significant differences between sexes. There were no significant differences between right and left gill rakers or filaments. However, males have higher gill raker counts compared with males; the reverse was however observed in the filaments. A comparison of gill rakers and filaments on gender basis indicated no significant differences.

Pearson's correlations showed two levels of significance: between weight and length and between gill meristics (Table 2). Partial correlations indicated that length has more influence on gill meristics compared with weight (Tables 3 and 4); while the absence of both parameters does not greatly affect interaction between gill parameters (Table 5).

The level of FA in gill rakers and filaments is presented in Figure 1. The rakers exhibited lower asymmetry compared with the filaments. The males had higher mean asymmetry for the gill rakers while the females recorded had for filaments. t-test indicated no significant differences between the sexes (Table 6). The gill filaments recorded higher mean asymmetry compared with rakers.

TABLE 1

Summary of body and gill parameters and gender comparison in Labeo ogunensis

\begin{tabular}{|c|c|c|c|c|c|}
\hline \multicolumn{2}{|l|}{ Parameters } & Range & Mean & $\begin{array}{l}\mathrm{t} \text {-statistic } \\
\text { by gender }\end{array}$ & $\begin{array}{l}\text { t-statistic } \\
\text { by side }\end{array}$ \\
\hline \multirow[t]{3}{*}{ Weight (g) } & M & $31.00-93.50$ & $54.23 \pm 17.53$ & & \\
\hline & F & $27.90-91.40$ & $63.24 \pm 16.17$ & -1.171 & \\
\hline & Total & 27.90-93.50 & $59.40 \pm 17.18$ & & \\
\hline \multirow[t]{3}{*}{ Length (cm) } & M & $11.50-16.20$ & $13.45 \pm 1.29$ & & \\
\hline & F & $11.30-16.00$ & $13.86 \pm 1.23$ & -0.702 & \\
\hline & Total & $11.30-16.20$ & $13.68 \pm 1.26$ & & \\
\hline \multirow[t]{3}{*}{ Gill rakers (L) } & M & $27.00-34.00$ & $30.00 \pm 2.17$ & & \\
\hline & $\mathrm{F}$ & $24.00-37.00$ & $31.62 \pm 2.67$ & & \\
\hline & Total & $24.00-37.00$ & $30.93 \pm 2.58$ & -2.110 & \\
\hline \multirow[t]{3}{*}{ (R) } & M & $27.00-34.00$ & $30.50 \pm 1.95$ & & -0.919 \\
\hline & F & $28.00-40.00$ & $31.74 \pm 2.78$ & & \\
\hline & Total & $24.00-37.00$ & $31.14 \pm 2.53$ & -2.238 & \\
\hline \multirow[t]{6}{*}{ Gill filament (L) } & M & $29.00-47.00$ & $34.15 \pm 4.12$ & & \\
\hline & F & $28.00-40.00$ & $35.37 \pm 2.93$ & & \\
\hline & Total & $28.00-47.00$ & $34.85 \pm 3.50$ & -0.952 & \\
\hline & M & $30.00-40.00$ & $34.75 \pm 2.73$ & & -1.150 \\
\hline & $\mathrm{F}$ & $28.00-40.00$ & $35.62 \pm 3.07$ & & \\
\hline & Total & $28.00-40.00$ & $35.25 \pm 2.93$ & -0.717 & \\
\hline
\end{tabular}


TABLE 2

Correlation matrix between body and gill parameters

$\begin{array}{lcccccc}\text { Parameters } & \text { Weight } & \text { Length } & \text { Left raker } & \text { Right raker } & \text { Left filament } & \text { Right filament Rakers (FA) } \\ \text { Length } & 0.941^{*} & & & & \\ \text { Left raker } & 0.145 & 0.183 & & & \\ \text { Right raker } & 0.136 & 0.205 & 0.808^{*} & & & \\ \text { Left filament } & 0.222 & 0.219 & 0.650^{*} & 0.529 * & 0.733^{*} & -0.114 \\ \text { Right filament } & 0.085 & 0.079 & 0.538^{*} & 0.476 & -0.559 & 0.154 \\ \text { Rakers (FA) } & -0.019 & 0.030 & -0.368 & 0.284 & -0.188 & 0.170 \\ \text { Filament (FA) } & -0.218 & -0.222 & -0.289 & & & \end{array}$

TABLE 3

Influence of Length on gill parameters of Labeo ogunensis

$\begin{array}{lrrrrrr}\text { Parameters } & \text { Length } & \text { Left rakers } & \text { Right raker } & \begin{array}{c}\text { Left } \\ \text { filament }\end{array} & \begin{array}{c}\text { Right } \\ \text { filament }\end{array} & \text { Rakers (FA) } \\ \text { Length } & & & & & & \\ \text { Left raker } & 0.1394 & & & & & \\ \text { Right rakers } & 0.2309 & 0.8401 & & & & \\ \text { Left filaments } & 0.0329 & 0.6408 & 0.5162 & & & \\ \text { Right filaments } & -0.0021 & 0.5333 & 0.4707 & 0.7350 & & \\ \text { Rakers (FA) } & 0.1412 & -0.3369 & 0.2889 & -0.2144 & -0.1133 & \\ \text { Filament (FA) } & -0.0503 & -0.2665 & -0.1635 & -0.5369 & 0.1774 & 0.1702\end{array}$

TABLE 4

Influence of weight on gill parameters of Labeo ogunensis

Parameters

Left raker

Right raker

Left Right filament filament

Rakers (FA)

Weight

Left raker

Right raker

Left filament

Right filament

Rakers (FA)

Filament (FA)

$\begin{array}{rr}-0.0821 & \\ -0.1731 & 0.5066 \\ 0.0457 & 0.6362 \\ 0.0307 & 0.5342 \\ -0.1394 & -0.3475 \\ 0.0282 & -0.2591\end{array}$

0.5066
0.4714
0.2837
-0.1490

0.7358
-0.2253

$-0.2253$

$-.1173$

$\begin{array}{lll}-0.1490 & -0.5367 & 0.1765\end{array}$

0.1814

TABLE 5

Influence of size on gill parameters of Labeo ogunensis

Parameters

Left rakers

Right raker

Left filament

Right filament

Rakers (FA)

Filament (FA)
Left raker

Right raker

Left filament

Right filament

0.8011

0.6428

0.5388

$-0.3637$

$-0.2624$

$$
\begin{aligned}
& 0.5230 \\
& 0.4842 \\
& 0.2661
\end{aligned}
$$

$-0.1563$
0.7355

$-0.2213$

$-0.5362$
$-0.1141$

0.1775
Rakers

0.1793 
TABLE 6

Fluctuating asymmetry in gills of $\mathrm{L}$. ogunensis

Gill parameters

Rakers (FA)

Filaments (FA)

M
F
Total

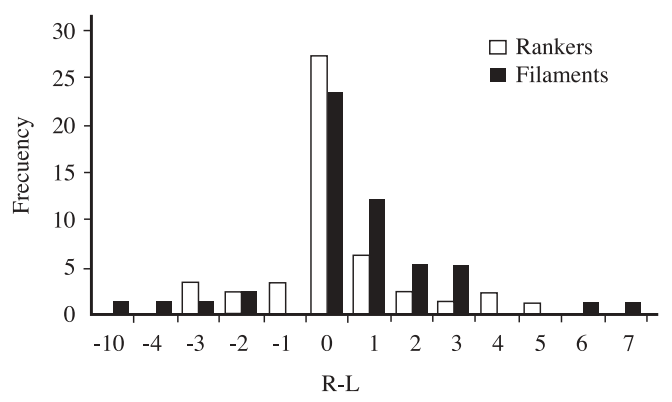

Fig. 1. Fluctuating asymmetry in gills of Labeo ogunensis.

\section{DISCUSSION}

Fluctuating asymmetry reflects the inability of the organism to perfectly control its development and this has been proposed as a measure of developmental stability (Van Valen 1962, Felley 1980). The FA observed in both the gill rakers and filaments of L. ogunensis agreed with earlier studies involving fish species from different water bodies (Felley 1980, Bengtsson et al. 1985, Graham et al. 1993, Sowunmi 2004) where varying degrees of FA were observed in response to environmental stress. Our results were able to compare asymmetry in two structures: gill rakers and filaments, on the same bilateral organ. This differs greatly from the common practice, of similar organs at different parts of the body as observed in studies using fins (Felley 1980, Bengtsson et al. 1985).

Since development proceeds on the basis of the same genotype under essentially identical conditions, developmental instability will be observed, according to Zakharov and

$\begin{array}{cc}\text { Mean }\left|\mathrm{R}_{\mathrm{i}}-\mathrm{L}_{\mathrm{i}}\right| & \text { t-statistic } \\ 0.35 \pm 0.98 & \\ 0.11 \pm 1.92 & -0.379 \\ \mathbf{0 . 2 1} \pm \mathbf{1 . 5 8} & \\ & \\ 0.25 \pm 1.28 & \\ 0.60 \pm 3.42 & -0.314 \\ \mathbf{0 . 4 3} \pm \mathbf{2 . 4 2} & \end{array}$

Yablokov (1990) and Graham et al. (1993), when population has been living under environmental stress. Jobling (1995) stated clearly that different parts of the gill are under similar genetic control, therefore the varied susceptibility could have arisen only from developmental interference capable of manifesting at microconcetrations or at submorbidity levels. Two possible origins have been implicated in asymmetry: genetic (endogenous) and environmental (exogenous). Exogenous influence was clearly manifest in this study (Bengtsson et al. 1985, Graham et al. 1993).

The filaments were found more sensitive on the basis of frequency of FA occurrence, contrary to patterns observed for Oreochromis niloticus and Clarias gariepinus (Sowunmi in press) where gill rakers exhibited higher FA, earlier workers did not make such comparison. The implication of this is that different parts of the gill exhibit varying susceptibility depending on the species and not necessarily types of stressors. Fish gills will probably be a better indicator of stress compared with other bilaterally symmetrical structures in fish. The gender influence in this study was considered minimal as most developmental interference did not appear sex dependent, it is important to note gender influence in fishes has not been earlier considered. The varied levels of correlations obtained showed that while correlations were observed between length and gill size, the pattern of asymmetry is not dependent on the size parameters vis: weight and length.

FA has been extensively used in many studies as acknowledged by literature, and highly recommended for environmental 
monitoring (GESAMP 1980) as simple and more reliable indicator of environmental perturbations compared with other indices because it detects perturbation and concentration considered non-harmful (Graham et al. 1993). Despite these advantages, it does not have widespread application, and information on FA pattern in tropical fish species is absent.

\section{RESUMEN}

Fluctuating asymmetry (FA), often used as indicator of environmental stress, was evaluated in gill rakers and filaments of Labeo ogunensis from Ogun river, Southwest Nigeria. Mean length and weight of $13.68 \pm 1.28 \mathrm{~cm}$ and $59.40 \pm 17.48 \mathrm{~g}$ were respectively recorded. The gill rakers $(\mathrm{t}=-0.919)$ and filaments $(\mathrm{t}=-1.150)$ from both sides were not significantly different. The gill filaments recorded $(0.31 \pm 2.42)$ higher incidence of fluctuating asymmetry (FA) compared with the gill rakers $(0.21 \pm 1.58)$, signifying developmental interference in the population. Fish size and sex were observed to exert minimal influence on FA.

\section{REFERENCES}

Adebisi, A.A. 1981 The physico-chemical hydrology of tropical seasonal river-upper Ogun river. Hydrobiologia 79: 157-165.

Bengtsson, B-E., Å. Bengtsson \& M. Himberg. 1985 Fish deformities and pollution in some Swedish waters. Ambio 14(1): 32-35.

Felley, J. 1980 Analysis of morphology and asymmetry in bluegill sunfish (Lepomis macrochirus) in the Southeastern United States. Copeia 1: 18-29.

GESAMP. 1980 Monitoring biological variables related to marine pollution. Rep. Stud. 12: 8-10.
Graham, J.H., D.C. Freeman \& J.M. Emleen 1993 Developmental stability: A sensitive indicator of populations under stress. In W.G. Landis, J.S. Hughes \& M.A. Lewis. (eds.). pp. 136-158. Environmental Toxicology and Risk Assessment, ASTM STP 1179, American Society for Testing and Materials, Philadelphia.

Hughes, G.M. 1995 Preliminary morphometric study of the gills of Oreochromis alcalicus grahami from Lake Magadi and a comparison with $O$. niloticus. J. Fish Biol. 47: 1102-1105.

Jobling, M. 1995 Environmental biology of fishes. Chapman and Hall London. pp. 93-136.

Kisia, S.M. \& G.M. Hughes. 1992. Estimation of oxygen diffusing capacity in the gills of different sizes of tilapia, Oreochromis niloticus. J. Zool. (Lond.) 227: 405-415.

Lucky, Z. 1977. Methods For The Diagnosis Of Fish Diseases. Amerind Pub. Co. PVT. Ltd. New Delhi. pp. 74.

Milton, S.W. 1999. Statistical methods in the biological and health sciences. WCB/McGraw-Hill, London. pp. 390-434.

Palmer, A.R. \& C. Strobeck. 1986. Fluctuating asymmetry: Measurements, Analysis, Patterns. Ann. Rev. Ecol. Syst. 17: 391-421.

Sokal, R.R. \& F.J. Rohlf 1987. Introduction to Biostatistics. W.H. Freeman, N.Y. pp. 49-120.

Sowunmi, A.A. 2004. Incidence of gill deformities and asymmetry in small fish population from Asejire reservoir, South-west Nigeria. West Afri. J. Appl. Ecol. (in press).

Van Valen, L. 1962. A study of fluctuating asymmetry. Evolution 16: 125-142.

Zacharov, V.A. \& A.V. Yablokov. 1990. Skull asymmetry in Baltic Grey Seal: Effects of environmental pollution. Ambio 19(5): 266-269. 
